\title{
Systemic abnormalities associated with retinal vein occlusion in young patients
}

\author{
This article was published in the following Dove Press journal: \\ Clinical Ophthalmology \\ 23 February 2017 \\ Number of times this article has been viewed
}

\author{
Suthasinee Sinawat ${ }^{1}$ \\ Chavisa Bunyavee ${ }^{2}$ \\ Tanapat Ratanapakorn' \\ Supat Sinawat ${ }^{3}$ \\ Wipada Laovirojjanakul' \\ Yosanan Yospaiboon' \\ 'KKU Eye Center, Department of \\ Ophthalmology, Faculty of Medicine, \\ Khon Kaen University, Khon \\ Kaen, Thailand; ' ${ }^{2}$ Department of \\ Ophthalmology, Faculty of Medicine, \\ Nawamindaradhiraj University, \\ Bangkok, Thailand; ${ }^{3}$ Department of \\ Physiology, Faculty of Medicine, Khon \\ Kaen University, Khon Kaen, Thailand
}

Correspondence: Yosanan Yospaiboon KKU Eye Center, Department of Ophthalmology, Faculty of Medicine, Khon Kaen University, I 23 Mitraparb Highway, Khon Kaen 40002, Thailand Tel +66 43348383

Email yosanan@kku.ac.th
Objectives: To study the systemic abnormalities associated with retinal vein occlusion in patients aged $\leq 50$ years with a particular emphasis on atherosclerotic diseases and thrombophilic disorders.

Methods: Medical charts of patients, aged $\leq 50$ years whose diagnoses were retinal vein occlusions during the period 1995-2015 were retrospectively reviewed. The primary outcome was the number of systemic abnormalities associated with these patients. Secondary outcomes included types of retinal vein occlusion and sites of occlusion.

Results: Atherosclerotic diseases were the most common systemic abnormalities associated with retinal vein occlusion and accounted for $55.1 \%$ of the patients in the study. Hypertension in $27.55 \%$, diabetes mellitus in $16.33 \%$, and $5.1 \%$ with dyslipidemia were noted. The number of thrombophilic disorders seemed to be less than expected and were noted in only $5.1 \%$. Other systemic abnormalities included viral hepatitis infection, systemic lupus erythematosus, and acquired immunodeficiency syndrome. Oral contraceptives were used by some patients.

Conclusion: Atherosclerotic diseases remained the most commonly associated systemic diseases in the majority of these patients. Approach to these patients should include a screening for hypertension, diabetes mellitus, and lipid abnormalities. Thrombophilia should also be considered where no obvious atherosclerotic diseases are found or if the patient is $<40$ years old, a history of thrombosis or a family history of thrombosis is possible.

Keywords: retinal vein occlusion, systemic diseases, young patients

\section{Introduction}

Retinal vein occlusion (RVO), the second most common retinal vascular disease after diabetic retinopathy, is one of the common causes of visual morbidity and blindness in the elderly population. ${ }^{1-3}$ RVO is classified into central retinal vein occlusion (CRVO) and branch retinal vein occlusion (BRVO) based on the site of vascular occlusion. CRVO is occlusion of the central retinal vein in the optic nerve at a variable distance posterior to the lamina cribrosa. ${ }^{4}$ BRVO, however, typically occurs at arteriovenous crossings of the branch retinal vein. The visual morbidity depends primarily on the type and location of the occlusion.

Although RVO is commonly seen in the elderly, with most cases occurring in patients $>65$ years, ${ }^{5}$ it can also occur in younger patients. ${ }^{6}$ While most elderly RVO patients have a history of atherosclerotic disease, hypertension, diabetes mellitus, or open angle glaucoma, ${ }^{7-10}$ the pathogenesis and risk factors for the disease in young patients are still unclear. Previous studies of these young patients revealed an association with thrombophilia, ${ }^{11-13}$ connective tissue diseases,,${ }^{14}$ antiphospholipid antibody syndrome, ${ }^{15-16}$ hyperhomocysteinemia, ${ }^{11,17}$ and hyperviscosity syndrome. ${ }^{18}$ Most of these studies, however, were case reports or small case studies, and there have been 
few reports on a large series of these patients. In this report, a large series of young RVO patients at a large referral eye center in Thailand was reviewed. The objective was to study the association of systemic abnormalities with RVO in these patients, particularly atherosclerotic diseases and thrombophilic disorders.

\section{Subjects and methods}

This study was approved by the Khon Kaen University Ethics Committee for Human Research (HE541385). Patient consents to review their medical records were not required by the ethics committee, as the case report forms had no link to the patient identities and the researcher respected the privacy of the patients. Medical charts of patients diagnosed with RVO during the period 1995-2015 were retrospectively reviewed. Only RVO patients aged $\leq 50$ years were included in the study. The majority of older RVO patients, were excluded. Demographic data included age, gender, disease duration, history of smoking, history of using/taking oral contraceptive pills in female patients, associated systemic diseases, fundus appearance, types of RVO, site of occlusion, and laboratory investigation. The primary outcome was the number of systemic diseases associated with these RVO patients. Secondary outcomes included types of RVO and sites of occlusion. The attending internists, cardiologists, endocrinologists, hematologists, and rheumatologists confirmed the definite diagnoses of the associated systemic abnormalities. The collected data were recorded and analyzed using SPSS for Windows version 20.0 (IBM SPSS, Chicago, IL, USA). Continuous data were reported as mean with standard deviation, and comparisons between data of each group were analyzed using two sample $t$-tests. Categorical data were compared via chi square and Fisher's exact tests. The statistical significance was defined at a $P$-value $<0.05$.

\section{Results}

A total of 98 patients (106 eyes) were recruited into the study. Seventy patients were diagnosed with CRVO and
30 patients were diagnosed with BRVO. Five patients had bilateral CRVO, one patient had bilateral BRVO, and two patients developed CRVO in one eye and BRVO in the other eye. This resulted in $75 \mathrm{CRVO}$ eyes and 31 BRVO eyes for investigation. The types of the occlusions are shown in Table 1. It was noted that BRVO increased with increasing age. In the patients aged $\leq 40$ years, CRVO was much more common than BRVO, whereas they were approximately the same in the 41-50 years age group.

The demographic data of these patients are shown in Table 2. The mean age of the patients was $36.5 \pm 8.7$ years in the CRVO group and $43 \pm 8.2$ years in the BRVO group. There was a significant difference in the mean ages between $\mathrm{CRVO}$ and BRVO groups $(P<0.001)$. In the gender data, CRVO was found in women more than men, whereas BRVO was noted in men more than women. These differences were not statistically significant $(P=0.315)$. RVO affected right eyes slightly more than left eyes. Both eyes were involved in $7.14 \%$ in the CRVO group and $3.33 \%$ in the BRVO group. Duration of onset prior to consulting ophthalmologists was about 50 days in CRVO and 60 days in BRVO groups $(P=0.505)$. There were two smokers, and 13 non-smokers in CRVO group; and one smoker, and three non-smokers in BRVO group. Most patients had missing data on smoking history.

When comparing initial visual acuities on presentation, most CRVO patients had poorer vision than BRVO patients, but there was no statistically significant difference $(P=0.054)$.

Fundus findings were similar to RVO in the elderly. There were diffuse retinal vein tortuosity and retinal hemorrhage in CRVO and localized lesions in BRVO patients. Disc swelling was noted in two cases. In BRVO eyes, the common site of occlusion was the superotemporal branch in 12 eyes, the inferotemporal branch in nine eyes, the inferior branch in six eyes, superior branch in one eye, superonasal branch in one eye and the macular branch in one eye.

Systemic abnormalities associated with RVO in these patients are shown in Table 3. The most common were

Table I Types of retinal vein occlusion in young patients

\begin{tabular}{|c|c|c|c|c|}
\hline Type of RVO & Age $\leq \mathbf{3 0}$ years & Age $31-40$ years & Age $4 I-50$ years & Total \\
\hline CRVO & $17(85)$ & $24(92.3)$ & $29(53.7)$ & $70 *(70)$ \\
\hline Unilateral CRVO & 14 & 21 & 26 & 61 \\
\hline Bilateral CRVO & 2 & 2 & I & 5 \\
\hline Combined CRVO \& CRAO in one eye & I & - & I & 2 \\
\hline CRVO in one eye \& BRVO in another eye & - & I & I & 2 \\
\hline BRVO & $3(15)$ & $2(7.7)$ & $25(46.3)$ & $30 *(30)$ \\
\hline Total & $20(100)$ & $26(100)$ & $54(100)$ & $100(100)$ \\
\hline
\end{tabular}

Notes: Results are shown in numbers of patients (\%). *Includes two patients with CRVO in one eye and BRVO in the other eye.

Abbreviations: RVO, retinal vein occlusion; CRVO, central retinal vein occlusion; CRAO, central retinal artery occlusion; BRVO, branch retinal vein occlusion. 
Table 2 Demographic data of the patients in the study

\begin{tabular}{llll}
\hline Demographic data & CRVO & BRVO & P-value \\
\hline Number of patients & $70 *$ & $30 *$ & \\
Age in years, mean \pm SD (range) & $36.5 \pm 8.7$ & $43 \pm 8.2$ & $<0.00$ I \\
& $(I 2-49)$ & $(I 7-49)$ & \\
Gender, n (\%) & & & $0.3 I 5$ \\
$\quad$ Males & $32(45.7 \%)$ & $17(56.7 \%)$ & \\
$\quad$ Females & $38(54.3 \%)$ & $13(43.3 \%)$ & \\
Onset in days, mean \pm SD (range) & $49.9 \pm 7 I .5$ & $60.5 \pm 75.2$ & 0.505 \\
& $(I-365)$ & $(3-90)$ & \\
Affected eyes, n (\%) & & & 0.198 \\
$\quad$ Right eyes & $28(40 \%)$ & $18(60 \%)$ & \\
$\quad$ Left eyes & $37(52.86 \%)$ & $I I(36.67 \%)$ & \\
Both eyes & $5(7.14 \%)$ & I (3.33\%) & \\
Initial VA in LogMAR, mean \pm SD & I.25 \pm 0.85 & $0.9 I \pm 0.66$ & 0.054 \\
(range) & $(0-3)$ & $(0.2-2)$ & \\
Median follow up (months) & 4.5 & 4.5 & \\
\hline
\end{tabular}

Notes: *Includes two patients with CRVO in one eye and BRVO in the other eye. Abbreviations: CRVO, central retinal vein occlusion; BRVO, branch retinal vein occlusion; VA, visual acuity; LogMAR, logarithm of the minimum angle of resolution; SD, standard deviation.

atherosclerotic diseases (55.1\%), including hypertension (27 cases), diabetes mellitus (16 cases), and dyslipidemia ( 5 cases). The next most commonly associated conditions were thrombophilic disorders (5.1\%), including protein $\mathrm{S}$ deficiency (two cases), antiphospholipid syndrome (one case) and protein $\mathrm{C}$ deficiency (one case) in the CRVO group and antiphospholipid syndrome (one case) in the BRVO group. These five patients were not diagnosed as thrombophilia before and had no other diseases found in the laboratory investigations. It is also noted from Table 3 that $29.59 \%$ of the patients had no systemic abnormalities confirmed by negative laboratory results.
Other systemic diseases that were also noted included viral hepatitis, rheumatoid arthritis, systemic lupus erythematosus, and acquired immunodeficiency syndrome. In addition, four patients who were taking oral contraceptive pills developed RVO, and one of these patients also had hypertension and severe pre-eclampsia. Three patients in CRVO group had taken oral contraceptive pills for 5-6 years and one patient in BRVO group had pills for 10 years; the type and dosage of the pills were not recorded.

Ocular diseases associated in these patients were nonproliferative diabetic retinopathy, chloroquine maculopathy, and orbital cellulitis. The patient with orbital cellulitis had combined CRVO and central retinal artery occlusion (CRAO) in the same eye.

Subgroup analysis was further performed on both CRVO and BRVO patients. The patients were divided into three subgroups depending on the age on presentation (age $\leq 30$, 31-40, and 41-50 years). It was noted that atherosclerotic diseases remained the major associated systemic diseases in both CRVO (Table 4) and BRVO patients (Table 5). Furthermore, it increased with advancing age. As in Table 3, hypertension was still the most common systemic disease in both CRVO and BRVO groups. It was particularly interesting that thrombophilic disorders were found only in the patients whose ages were $\leq 40$ years.

\section{Discussion}

Although RVO is often associated with systemic atherosclerotic diseases such as hypertension, diabetes mellitus, and dyslipidemia, ${ }^{7-10}$ the cause and effect has not been proven

Table 3 Systemic abnormalities associated with RVO in young patients

\begin{tabular}{|c|c|c|c|}
\hline Systemic abnormalities & CRVO $(\mathrm{n}=70 *)$ & BRVO $(n=30 *)$ & Total $(n=98)$ \\
\hline No systemic diseases & $25(35.7 I)$ & $4(13.33)$ & 29 (29.59) \\
\hline Atherosclerotic diseases & $32(45.7 I)$ & $22(73.33)$ & $54(55.1)$ \\
\hline Hypertension & 18 & 9 & 27 \\
\hline Diabetes mellitus & 8 & 8 & 16 \\
\hline Hypertension and diabetes mellitus & 4 & 2 & 6 \\
\hline Dyslipidemia & 2 & 3 & 5 \\
\hline Thrombophilic disorders & $4(5.7 I)$ & I (3.33) & $5(5.1)$ \\
\hline Protein S deficiency & 2 & - & 2 \\
\hline Protein C deficiency & $\mathrm{I}$ & - & I \\
\hline Antiphospholipid syndrome & I & I & 2 \\
\hline Other diseases & $4(5.7 I)$ & $3(10)$ & $7(7.14)$ \\
\hline Hepatitis B & - & I & 1 \\
\hline Hepatitis C & 1 & - & 1 \\
\hline Rheumatoid arthritis & $\mathrm{I}$ & & $\mathrm{I}$ \\
\hline Systemic lupus erythrematosus & I & I & 2 \\
\hline G6PD deficiency & - & 1 & 1 \\
\hline Acquired immune deficiency & $\mathrm{I}$ & - & $\mathrm{I}$ \\
\hline
\end{tabular}

Notes: The results are shown in numbers of patients (\%). *Includes two patients with CRVO in one eye and BRVO in the other eye. Abbreviations: CRVO, central retinal vein occlusion; BRVO, branch retinal vein occlusion; G6PD, glucose-6-phosphate dehydrogenase. 
Table 4 Subgroup analysis of systemic abnormalities associated with CRVO in young patients

\begin{tabular}{|c|c|c|c|c|}
\hline Systemic abnormalities & $\begin{array}{l}\text { Age } \leq \mathbf{3 0} \text { years } \\
(\mathrm{n}=17)\end{array}$ & $\begin{array}{l}\text { Age } 3 I-40 \text { years } \\
(n=24)\end{array}$ & $\begin{array}{l}\text { Age } 4 I-50 \text { years } \\
(n=29)\end{array}$ & $\begin{array}{l}\text { Total } \\
(n=70 *)\end{array}$ \\
\hline Atherosclerotic diseases & $3(17.65)$ & $10(41.67)$ & $19(65.52)$ & $32(45.7 I)$ \\
\hline Hypertension & 3 & 6 & 9 & 18 \\
\hline Diabetes mellitus & - & 3 & 5 & 8 \\
\hline Hypertension and diabetes mellitus & - & I & 3 & 4 \\
\hline Dyslipidemia & - & - & 2 & 2 \\
\hline Thrombophilic disorders & $2(11.76)$ & $2(8.33)$ & - & $4(5.7 I)$ \\
\hline Protein S deficiency & 1 & 1 & - & 2 \\
\hline Protein C deficiency & - & I & - & 1 \\
\hline Antiphospholipid syndrome & I & - & - & 1 \\
\hline Other diseases & I (5.88) & $2(8.33)$ & I (3.45) & $4(5.7 I)$ \\
\hline Hepatitis C & - & I & - & 1 \\
\hline Rheumatoid arthritis & - & - & 1 & 1 \\
\hline Systemic lupus erythrematosus & I & - & - & 1 \\
\hline Acquired immune deficiency & - & 1 & - & 1 \\
\hline
\end{tabular}

Notes: The results are shown in numbers of patients (\%). *Includes two patients with CRVO in one eye and BRVO in the other eye.

Abbreviations: CRVO, central retinal vein occlusion; BRVO, branch retinal vein occlusion.

and the pathogenesis is still unclear. Hayreh demonstrated that the pathogenesis of CRVO was very different from that of BRVO. ${ }^{4} \mathrm{CRVO}$ was usually caused by thrombosis in the central retinal vein and occlusion in the optic nerve at a variable distance posterior to the lamina cribrosa. ${ }^{4}$ Atherosclerosis of the central retinal artery causes abnormal perivascular changes and altered hematological factors in the adjacent central retinal vein, contributing to venous thrombosis and CRVO. ${ }^{19}$ Conversely, BRVO is typically caused by the compression of the branch retinal vein at the arteriovenous crossing by the branch retinal artery, which shares a common adventitial sheath. ${ }^{4,19}$

A previous study revealed that RVO occurred between the ages of 14 and 92 years; however, $51 \%$ of all RVO patients had their first episode at $\geq 65$ years. ${ }^{5}$
In a multi-centered Pathological Determinants of Atherosclerosis in Youth (PDAY) research program, Wissler and Strong demonstrated that a large number of young adults had evidence of atherosclerosis, and the extent of atherosclerotic lesions increased steadily from $15-34$ years. ${ }^{20}$ This is a reason why atherosclerotic disease is also a significant associated systemic disease in the current study, although the patients have a mean age of 36-years-old in the CRVO group and 43-years-old in the BRVO group. In addition, all five bilateral CRVOs occurred in the patients aged 28-35 years old, whereas one bilateral BRVO patient was aged 48 -years-old.

It has already been known that BRVO was more common than CRVO in the elderly. ${ }^{1-3}$ The Beaver Dam Eye Study reported the 15-year cumulative incidences of BRVO and

Table 5 Subgroup analysis of systemic abnormalities associated with BRVO in young patients

\begin{tabular}{|c|c|c|c|c|}
\hline Systemic abnormalities & $\begin{array}{l}\text { Age } \leq 30 \text { years } \\
(n=3)\end{array}$ & $\begin{array}{l}\text { Age } 3 I-40 \text { years } \\
(n=2)\end{array}$ & $\begin{array}{l}\text { Age } 41-50 \text { years } \\
(n=25)\end{array}$ & $\begin{array}{l}\text { Total } \\
(\mathrm{n}=30 *)\end{array}$ \\
\hline Atherosclerotic diseases & I (33.33) & - & $21(84)$ & $22(73.33)$ \\
\hline Hypertension & I & - & 8 & 9 \\
\hline Diabetes mellitus & - & - & 8 & 8 \\
\hline Hypertension and diabetes mellitus & - & - & 2 & 2 \\
\hline Dyslipidemia & - & - & 3 & 3 \\
\hline Thrombophilic disorders & I (33.33) & - & - & I (3.33) \\
\hline Protein S deficiency & - & - & - & - \\
\hline Protein $\mathrm{C}$ deficiency & - & - & - & - \\
\hline Antiphospholipid syndrome & I & - & - & I \\
\hline Other diseases & - & $2(8.33)$ & - & $2(6.67)$ \\
\hline Hepatitis B & - & I & - & I \\
\hline G6PD deficiency & - & I & - & I \\
\hline
\end{tabular}

Notes: The results are shown in numbers of patients (\%). *Includes two patients with CRVO in one eye and BRVO in the other eye.

Abbreviations: CRVO, central retinal vein occlusion; BRVO, branch retinal vein occlusion; G6PD, glucose-6-phosphate dehydrogenase. 
CRVO were $1.8 \%$ and $0.5 \% .^{2}$ Conversely, this study found young CRVO much more common than BRVO. The reason for this discrepancy is still unknown. It may be attributed to the fact that sclerotic changes increase with age. Sclerotic changes in the small branch retinal arteries are less in the young than those in the elderly, therefore these changes result in less compression on the adjacent small branch veins at the arteriovenous crossing in BRVO. Therefore, BRVO was less common in the young but increased with increasing age. The subgroup analyses in Tables 4 and 5 show this increasing trend and seem to validate this hypothesis.

This study also showed that young CRVO occurrence was also found in women more than men, and young BRVO was noted in men more than women. However, these differences were not statistically significant. Some previous studies on RVO in the elderly demonstrated more prevalence in women than men. ${ }^{2,3,19}$ Another study, however, reported more in men than women and indicated that being male was one of the risk factors in the development of RVO. ${ }^{6}$

Previous studies proposed that thrombophilia and coagulation disorders played significant roles in the development of RVO in young patients. ${ }^{11-13}$ The current study, however, demonstrated that these disorders are not so common in young RVO patients. Only two cases of protein $\mathrm{S}$ deficiency, one case of protein $\mathrm{C}$ deficiency and two cases of antiphospholipid syndrome were found. These findings agree well with the study of Ahluwalia et al. ${ }^{21}$ They concluded that thrombophilic risk factors were not commonly associated with RVO in young patients, and that investigations of other factors that contribute to the development of RVO in the young should be further studied. ${ }^{21}$

Infectious diseases and connective tissue diseases were also systemic abnormalities associated with RVO in the current study. There was one patient with hepatitis B virus infection who developed BRVO and another patient with hepatitis $\mathrm{C}$ virus infection developed CRVO. These findings agreed well with previous studies, which demonstrated that viral hepatitis might promote the development of venous thromboembolism. ${ }^{22,23}$ The imbalance between procoagulant and anticoagulant factors associated with chronic liver disease might have clinical implications. ${ }^{22}$ Moreover, RVO described in chronic hepatitis $\mathrm{C}$ was usually attributed to the treatment with interferon. ${ }^{24}$ It seemed probable that a combination of active hepatitis $\mathrm{C}$ virus infection in a genetically susceptible individual receiving interferon accounted for the RVO. ${ }^{25}$

Komolafe and Ashaye reported combined CRAO and CRVO complicating orbital cellulitis. ${ }^{26}$ In this study, there was also one patient with orbital cellulitis who developed this combined occlusion. This might be attributed to that the site of occlusion is at or close to the lamina cribrosa so that there is a complete block of CRV with a sudden increase in retinal venous pressure and consequently causes secondary CRAO due to hemodynamic block. ${ }^{4}$

Systemic lupus erythematosus (SLE) is a chronic autoimmune disease that can affect any part of the human body including the eyes. CRVO is one of the common ocular complications. Antiphospholipid antibody is usually associated with large vessel occlusions in SLE patients. ${ }^{15,27}$ In this study there was one case of an SLE patient who presented with RVO but the antiphospholipid antibody was negative. There was another SLE patient, however, with positive antiphospholipid antibody who developed BRVO mentioned above in the thrombophilic group. Yen et al investigated the risk of developing RVO in patients with SLE. ${ }^{28}$ They reported the incidence of RVO was 3.46-times higher in the SLE group than in controls and concluded that SLE was significantly associated with an increased risk of developing RVO. Screening for antiphospholipid antibody was therefore necessary in SLE patients with lupus retinopathy, as prompt treatment with anticoagulants was important to prevent further blinding complications. ${ }^{28}$

Matsuo et al investigated the incidence of ocular complications in patients with rheumatoid arthritis and found CRVO in $1.8 \%$ of their patients in their rheumatologic clinic. ${ }^{29}$ Moreover, Meyer et al reported 3 patients with rheumatoid arthritis who developed RVO after application of rofecoxib, a cyclooxygenase 2 inhibitor. ${ }^{30}$ Although the drugs are safe in the majority of patients, under certain conditions they may induce prothrombotic effects. A few patients with predisposed thrombosis may be at risk for cardiovascular and ocular thrombotic events. In the current study, there were two patients with rheumatoid arthritis who developed RVO. Neither of them had a history of using a cyclooxygenase 2 inhibitor.

Glucose-6-phosphate dehydrogenase (G6PD) deficiency is the most common human enzyme deficiency, affecting people worldwide. It increases erythrocyte vulnerability to oxidative stress and may precipitate episodes of hemolysis when individuals are exposed to triggering agents. Hemolytic anemia may contribute to thrombosis as a result of increased erythrocyte aggregation and erythrocyte-endothelium interaction. ${ }^{31}$ Pinna et al demonstrated that G6PD deficiency was found in $4.7 \%$ of patients with RVO compared to $11.9 \%$ of control subjects and concluded that this enzyme deficiency was significantly associated with decreased risk 
of development of RVO. ${ }^{32}$ In this study there was one case of G6PD deficiency who developed BRVO.

In this study one patient presented with CRVO as the initial manifestation of AIDS. A previous study also reported CRVO as an initial sign in a patient with IDSS. $^{33}$ In a clinicopathologic study, ${ }^{34}$ there was no evidence of HIV in vascular endothelial cells using electron microscopy and in situ hybridization techniques. This finding suggested that other factors were probably responsible for the development of vascular occlusion. ${ }^{34}$

In the current study there were four patients on oral contraceptive pills who developed CRVO. One patient also had severe hypertension and pre-eclampsia, whereas the other three patients had no other systemic diseases. Previous studies proposed oral contraceptive pills as a risk factor for $\mathrm{RVO}^{35,36}$ and recommended periodic physical examinations for young women on oral contraceptive pills, even if no systemic diseases are detected. ${ }^{35}$ A survey in 2013 demonstrated that women currently using combined oral contraceptives had a twofold risk of venous thrombosis compared to non-users. ${ }^{36}$

In conclusion, the most commonly associated systemic abnormalities in young RVO patients are still atherosclerotic diseases. Thrombophilic disorders are not so common. Infectious diseases, connective tissue diseases and acquired immunodeficiency syndrome may also be associated with RVO in young patients. Female patients on oral contraceptives also have a higher risk for development of RVO.

The strength of this study is that it is a large series of young RVO patients collected for over 20 years from a large tertiary-care eye center in Thailand, whereas the limitation is incompleteness and missing data due to the retrospective nature of the study; smoking history is an example as most patients had missing data on history of smoking. The complete thrombophilic workup is also a potential limitation of the study. It is not routinely performed in all patients. Only RVO patients who aged $\leq 40$ years have completed the workups. Those RVO patients aged $41-50$ years with no obvious atherosclerotic disorders were furthered investigated for thrombophilic disorders. Moreover, some patients with diagnosis of papillophlebitis may be excluded from the electronic database of RVO patients. This also makes the collected data incomplete. The results, however, can give some indications that these young RVO patients have clinical manifestations and associated systemic diseases not much different from RVO in the elderly. Atherosclerotic diseases remain a major problem in the same fashion as reported in the elderly. The association of RVO with systemic cardiovascular diseases emphasizes the need to investigate cardiovascular risk factors in these young patients. Evaluation must include a screening for hypertension, diabetes mellitus, and lipid abnormalities. Thrombophilia should also be considered where no obvious atherosclerotic diseases are found or if the patient is $<40$-years-old, has a history of thrombosis or a family history of thrombosis.

\section{Acknowledgments}

The authors thank Dr Kaewjai Thepsuthammarat, Clinical Epidemiology Unit, Faculty of Medicine, Khon Kaen University for statistical analysis; and Professor James A Will, University of Wisconsin for assistance with the English language presentation of the manuscript. This study was supported by invitation research grant (I 56215) from the Faculty of Medicine, Khon Kaen University.

\section{Disclosure}

The authors report no conflicts of interest in this work.

\section{References}

1. Klein R, Klein BE, Moss SE, Meuer SM. The epidemiology of retinal vein occlusion: the Beaver Dam Eye Study. Trans Am Ophthalmol Soc. 2000;98:133-141

2. Klein R, Moss SE, Meuer SM, Klein BE. The 15-year cumulative incidence of retinal vein occlusion: the Beaver Dam Eye Study. Arch Ophthalmol. 2008;126(4):513-518.

3. Cugati S, Wang JJ, Rochtchina E, Mitchell P. Ten-year incidence of retinal vein occlusion in an older population: the Blue Mountains Eye Study. Arch Ophthalmol. 2006;124:726-732.

4. Hayreh SS. Prevalent misconceptions about acute retinal vascular occlusive disorders. Prog Retin Eye Res. 2005;24:493-519.

5. Hayreh SS, Zimmerman MB, Podhajsky P. Incidence of various types of retinal vein occlusion and their recurrence and demographic characteristics. Am J Ophthalmol. 1994;117:429-441.

6. Fong AC, Schatz H. Central retinal vein occlusion in young adults. Surv Ophthalmol. 1993;37:393-417.

7. Rath EZ, Frank RN, Shin DH, Kim C. Risk factors for retinal vein occlusions. A case-control study. Ophthalmology. 1992;99: 509-514.

8. The Eye Disease Case-Control Study Group. Risk factors for central retinal vein occlusion. Arch Ophthalmol. 1996;114:45-554.

9. The Eye Disease Case-Control Study Group. Risk factors for branch retinal vein occlusion. Am J Ophthalmol. 1993;116:286-296.

10. Koizumi H, Ferrara DC, Brue C, Spaide RF. Central retinal vein occlusion case-control study. Am J Ophthalmol. 2007;144(6):858-863.

11. Marcucci R, Bertini L, Giusti B, et al. Thrombophilic risk factors in patients with central retinal vein occlusion. Thromb Haemost. 2001; $86: 772-776$.

12. Fegan CD. Central retinal vein occlusion and thrombophilia. Eye (Lond). 2002;16:98-106.

13. Rehak M, Krcova V, Slavik L, et al. The role of thrombophilia in patients with retinal vein occlusion and no systemic risk factors. Can J Ophthamol. 2010;45:171-175.

14. Batioğlu F, Atmaca LS, Karabulut HG, Beyza Sayin D. Factor V Leiden and prothrombin gene G20210A mutations in ocular Behcet disease. Acta Ophthalmol Scand. 2003;81:283-285.

15. Paccalin M, Manic H, Bouche G, et al. Antiphospholipid syndrome in patients with retinal venous occlusion. Thromb Res. 2006;117:365-369. 
16. Asherson RA, Merry P, Acheson JF, Harris EN, Hughes GR. Antiphospholipid antibodies: a risk factor for occlusive ocular vascular disease in systemic lupus erythematosus and the 'primary' antiphospholipid syndrome. Ann Rheum Dis. 1989;48:358-361.

17. Vine AK. Hyperhomocysteinemia: a new risk factor for central retinal vein occlusion. Trans Am Ophthalmol Soc. 2000;98:493-503.

18. Chiang CC, Begley S, Henderson SO. Central retinal vein occlusion due to hyperviscosity syndrome. J Emerg Med. 2000;18:23-26.

19. Yau JW, Lee P, Wong TY, Best J, Jenkins A. Retinal vein occlusion: an approach to diagnosis, systemic risk factors and management. Intern Med J. 2008;38:904-910.

20. Wissler RW, Strong JP, the PDAY Research Group. Risk factors and progression of atherosclerosis in youth. Am J Pathol.1998;153: 1023-1033.

21. Ahluwalia J, Rao S, Varma S, et al. Thrombophilic risk factors are uncommon in young patients with retinal vein occlusion. Retina. 2015; 35(4): 715-719.

22. Galli L, Gerdes VE, Guasti L, Squizzato A. Thrombosis Associated with Viral Hepatitis. J Clin Transl Hepatol. 2014;2(4):234-239.

23. Devin F, Roques G, Disdier P, Rodor F, Weiller PJ. Occlusion of central retinal vein after hepatitis B vaccination. Lancet. 1996;347:1626.

24. Kim ET, Kim LH, Lee JI, Chin HS. Retinopathy in hepatitis C patients due to combination therapy with pegylated interferon and ribavirin Jpn J Ophthalmol. 2009;53(6):598-602.

25. Nadir A, Amin A, Chalisa N, van Thiel DH. Retinal vein thrombosis associated with chronic hepatitis $\mathrm{C}$ : a case series and review of the literature. J Viral Hepat. 2000;7(6):466-470.

26. Komolafe OO, Ashaye AO. Combined central retinal artery and vein occlusion complicating orbital cellulitis. Niger J Clin Pract. 2008;11(1): 74-76.
27. Hong-Kee N, Mei-Fong C, Azhany Y, Zunaina E. Antiphospholipid syndrome in lupus retinopathy. Clin Ophthalmol. 2014;8:2359-2363.

28. Yen YC, Weng SF, Chen HA, Lin YS. Risk of retinal vein occlusion in patients with systemic lupus erythematosus: a population-based cohort study. Br J Ophthalmol. 2013;97(9):1192-1196.

29. Matsuo T, Kono R, Matsuo N, et al. Incidence of ocular complications in rheumatoid arthritis and the relation of keratoconjunctivitis sicca with its systemic activity. Scand J Rheumatol. 1997;26(2):113-116.

30. Meyer CH, Schmidt JC, Rodrigues EB, Mennel S. Risk of retinal vein occlusions in patients treated with rofecoxib (vioxx). Ophthalmologica. $2005 ; 219(4): 243-247$.

31. Kotwal RS, Butler FK Jr, Murray CK, Hill GJ, Rayfield JC, Miles EA. Central retinal vein occlusion in an Army ranger with glucose-6-phosphate dehydrogenase deficiency. Mil Med. 2009;174(5):544-547.

32. Pinna A, Carru C, Solinas G, Zinellu A, Carta F. Glucose-6-phosphate dehydrogenase deficiency in retinal vein occlusion. Invest Ophthalmol Vis Sci. 2007; 48(6):2747-2752.

33. Biswas J, Deka S, Padmaja S, Madhavan HN, Kumarasamy N, Solomon S. Central retinal vein occlusion due to herpes zoster as the initial presenting sign in a patient with acquired immunodeficiency syndrome (AIDS). Ocul Immunol Inflamm. 2001;9(2):125-130.

34. Friedman SM, Margo CE. Bilateral central retinal vein occlusions in a patient with acquired immunodeficiency syndrome. Clinicopathologic correlation. Arch Ophthalmol. 1995;113(9):1184-1188.

35. Aggarwal RS, Mishra VV, Aggarwal SV. Oral contraceptive pills: A risk factor for retinal vascular occlusion in in-vitro fertilization patients. J Hum Reprod Sci. 2013;6(1):79-81.

36. Eichinger S, Evers JLH, Glasier A, et al. Venous thromboembolism in women: A specific reproductive health risk. Human Reproduction Update. 2013;19(5):471-482.
Clinical Ophthalmology

\section{Publish your work in this journal}

Clinical Ophthalmology is an international, peer-reviewed journa covering all subspecialties within ophthalmology. Key topics include: Optometry; Visual science; Pharmacology and drug therapy in eye diseases; Basic Sciences; Primary and Secondary eye care; Patient Safety and Quality of Care Improvements. This journal is indexed on

Submit your manuscript here: http://www.dovepress.com/clinical-ophthalmology-journal

\section{Dovepress}

PubMed Central and CAS, and is the official journal of The Society of Clinical Ophthalmology (SCO). The manuscript management system is completely online and includes a very quick and fair peer-review system, which is all easy to use. Visit http://www.dovepress.com/ testimonials.php to read real quotes from published authors. 